\title{
Characterization of Cytochromes in Lithotrophically and Organotrophically Grown Cells of Thiobacillus A2
}

\author{
By S. LOYA, ${ }^{*}$ S. A. YANKOFSK Y ${ }^{1}$ AND B. L. EPEL ${ }^{2}$ \\ Departments of Microbiology ${ }^{1}$ and Botany ${ }^{2}$, The George $S$. Wise Faculty of Life Sciences, \\ Tel Aviv University, Ramat Aviv 69978, Israel
}

(Received 28 October 1981; revised 3 February 1982)

\begin{abstract}
The dominant cytochrome in thiosulphate-grown Thiobacillus A2 was found to be of the $c$-type with a reduced $\alpha$-band at $548 \mathrm{~nm}\left(c_{548}\right)$. This $c_{548}$ component did not constitute an integral part of the membrane carrier system. It did, however, appear to be part of a large complex not tightly bound to membranes. Reconstitution experiments showed that cytochromes of the membrane ' $a b c$ ' system could be reduced by the $c_{548}$ component and vice versa. The reduction of membrane cytochromes of either lithotrophic or organotrophic origin by thiosulphate electrons was achieved, but it required the presence of a soluble fraction containing cytochrome $c_{548}$. Evidence tending to rule out a reductive cleavage as the first step of the thiosulphate oxidation pathway in Thiobacillus A2 was obtained by following the reduction of partially purified $c_{548}$ particles under various conditions.
\end{abstract}

\section{INTRODUCTION}

A seemingly general characteristic of lithotrophic micro-organisms, including the thiobacilli, is their strikingly high cytochrome content (Smith \& Hoare, 1977; Tonge et al., 1974; Charles, 1971; Tikhonova et al., 1967; Aleem, 1965; Trudinger, 1961). A case in point is Thiobacillus A2. Growth of this facultatively chemolithotrophic bacterium on thiosulphate induces much higher levels of cytochrome $c$ than does corresponding culture on an organic substrate (Taylor \& Hoare, 1969 ; Kula et al., 1975; Loya et al., 1982). In contrast to other cellular cytochromes, synthesis of the cytochrome $c_{548}$ component specifically associated with lithotrophic cells does not resume after adaptation of such cells to organotrophic growth on succinate (Loya et al., 1982). Direct evidence for participation of cytochrome $c_{548}$ in the lithotrophic energy metabolism of Thiobacillus $\mathrm{A} 2$ is presented below.

\section{METHODS}

Growth of bacteria and preparation of extracts. Growth of aerobic cultures of Thiobacillus A2N on sodium thiosulphate $(20 \mathrm{mM})$ or sodium succinate $(20 \mathrm{mM})$ has been described elsewhere (Loya et al., 1982). Cells harvested from thiosulphate cultures (at densities of about $5 \times 10^{7} \mathrm{ml}^{-1}$ ) are referred to as 'lithotrophic cells', while those recovered from succinate cultures (at densities of about $5 \times 10^{8} \mathrm{ml}^{-1}$ ) are designated 'organotrophic cells'. Harvested cells, washed twice with potassium phosphate buffer (100 mM, pH 7.0) containing $1 \mathrm{~mm}-\mathrm{MgCl}_{2}$ and suspended in the same buffer at densities up to 500 -fold greater than in the original culture, were disrupted by sonication (Loya et al., 1982). After centrifugation of sonicates at $20000 \mathrm{~g}, 4^{\circ} \mathrm{C}$ for $30 \mathrm{~min}$, the resulting $20000 \mathrm{~g}$ supernatant, designated the 'crude extract', was either stored frozen at $-40^{\circ} \mathrm{C}$ or further fractionated by centrifugation at $144000 \mathrm{~g}, 4^{\circ} \mathrm{C}$ for $2 \mathrm{~h}$ (Loya et al., 1982). The resultant $144000 \mathrm{~g}$ supernatant and pellet (the latter resuspended in 1 vol. phosphate/magnesium buffer), referred to as the 'soluble' and 'membrane' fraction respectively, were also stored frozen at $-40^{\circ} \mathrm{C}$ (Loya et al., 1982).

Gel chromatography. Wet beads of Sepharose 6B (Pharmacia), suspended in phosphate buffer (100 mM, pH 7.0) were packed in a glass column $(1.8 \mathrm{~cm}$ diam.) to a height of $95 \mathrm{~cm}$. The void volume of the column, determined with Blue Dextran 2000 (Pharmacia) was $77 \mathrm{ml}$. Apparent particle weights of components eluted from the column were estimated by reference to the elution of the markers bovine serum albumin (Sigma, mol. wt 63000) and horse heart cytochrome $c$ (Sigma, mol. wt 13000). A sample of $25.9 \mathrm{mg}$ soluble protein in $2.0 \mathrm{ml}$ phosphate/magnesium 
buffer was loaded and eluted (with phosphate buffer) at a flow rate of $15 \mathrm{ml} \mathrm{h}^{-1}$. All operations were performed at $4{ }^{\circ} \mathrm{C}$ and fractions of $3.2 \mathrm{ml}$ collected. The relative protein and cytochrome content of each fraction was estimated by measuring the absorbance at 280 and $410 \mathrm{~nm}$, respectively.

Spectrometry. Absolute absorption spectra of samples containing 2-12 mg extract protein in 0.5-2.0 ml phosphate/magnesium or phosphate buffer (see above) were recorded from 650 to $500 \mathrm{~nm}$ in a single-beam spectrophotometer linked to a minicomputer (Loya et al., 1982). Reduced minus oxidized difference spectra were computer-generated from the absolute spectra of the reduced and oxidized samples. Reduction was achieved with dithionite, succinate or thiosulphate. In the last case, thiosulphate oxidizing activity was measured by following the reduction kinetics of cytochrome $c$ endogenous to the sample tested. The reaction was started by addition of reductant and scans were repeated at timed intervals until further rises in $\alpha$-band peak heights were no longer observed. The time required for maximal cytochrome reduction by thiosulphate, a function of sample protein content, was routinely $30-45 \mathrm{~min}$.

\section{RESULTS}

\section{Chemical reduction of cytochromes in cell-free extracts}

The dithionite-reduced minus oxidized difference spectrum of a crude extract from lithotrophic cells (Fig. 1, trace A) was similar to that previously obtained with intact cells (Loya et al., 1982). Based on peak location, the presence of a $c$-type cytochrome with an $\alpha$-band at $548 \mathrm{~nm}$ (cytochrome $c_{548}$ ), and of a cytochrome oxidase of the $a$-type with an $\alpha$-band at $603 \mathrm{~nm}$ (cytochrome $\left.a_{603}\right)$ was indicated. Following high-speed centrifugation $(144000 \mathrm{~g}, 2 \mathrm{~h})$ cytochrome $c_{548}$ was found almost exclusively in the high-speed supernatant (Fig. 1, trace B). In contrast, cytochrome oxidase was confined to the pellet (Fig. 1, trace C). In the absence of the masking effect of cytochrome $c_{548}$, two additional cytochromes were resolved in the pellet fraction on the basis of their $\alpha$-bands: an apparent $c$-type cytochrome with an $\alpha$-band at $550 \mathrm{~nm}$ (cytochrome $c_{550}$ ), and an apparent $b$-type cytochrome with an $\alpha$-band (a shoulder in the spectrum) around $560 \mathrm{~nm}$ (cytochrome $b_{560}$; Fig. 1, trace C). The membrane-associated cytochrome $c_{550}$ represented about $16 \%$ of total cytochrome $c$ content in lithotrophic cells (Table 1).

The dithionite-reduced minus oxidized difference spectrum of a crude extract from organotrophic cells was markedly different from that of a corresponding preparation from lithotrophic cells. It did, however, resemble the spectrum of the lithotrophic membrane fraction. Based on specific absorbance at peak wavelength, the concentration of $c$-type cytochromes was 10 -fold lower in succinate-grown cells than in thiosulphate-grown cells (Table 1). Furthermore, the absorption maximum of the major $c$-type cytochrome in succinate-grown cells was $550 \mathrm{~nm}$ rather than $548 \mathrm{~nm}$. Indeed, the major $c$-type cytochrome in succinate-grown cells was spectrally similar to the $c$-type cytochrome found in the pellet fraction of thiosulphate-grown cells. In addition to the absorption band at $550 \mathrm{~nm}$ observed in the reduced minus oxidized difference spectrum of crude extract from organotrophic cells, there were at least three additional reduced $\alpha$-bands; at about $555 \mathrm{~nm}, 560 \mathrm{~nm}$ and $603 \mathrm{~nm}$. The $560 \mathrm{~nm}$ band probably represents a $b$-type cytochrome, while the $603 \mathrm{~nm}$ band is the $\alpha$-band of cytochrome oxidase. The $555 \mathrm{~nm}$ band could either be that of a long-wavelength $c$-type or a short-wavelength $b$-type cytochrome.

Of the total $c$-type cytochrome present in a crude extract from organotrophic cells (Fig. 2, trace A) $90 \%$ appeared in the membrane fraction following high speed centrifugation (Fig. 2, trace B; Table 1). Qualitatively, the membrane fractions from lithotrophic (Fig. 1, trace C) and organotrophic cells (Fig. 2, trace B) resemble one another. Similarly, the soluble fraction from succinate-grown cells contained a component with spectral properties not unlike those of the lithotrophic $c_{548}$ component (Fig. 2, trace C). Nevertheless, in contrast to the lithotrophically grown bacteria, the amount of $c_{548}$-like cytochrome in the organotrophic soluble fraction was small.

\section{Substrate reduction of cytochromes in cell extracts}

Sonication of lithotrophic cells resulted in drastic loss of their capacity to oxidize thiosulphate. The rate of thiosulphate-promoted oxygen consumption per mg cell protein was characteristically $600 \mathrm{nmol} \mathrm{min}-1$ prior to cell rupture, and only $1-3 \mathrm{nmol} \mathrm{min}^{-1}$ after sonication. Nonetheless, it remained possible to follow thiosulphate-dependent reduction of cytochromes in cell-free extracts. 


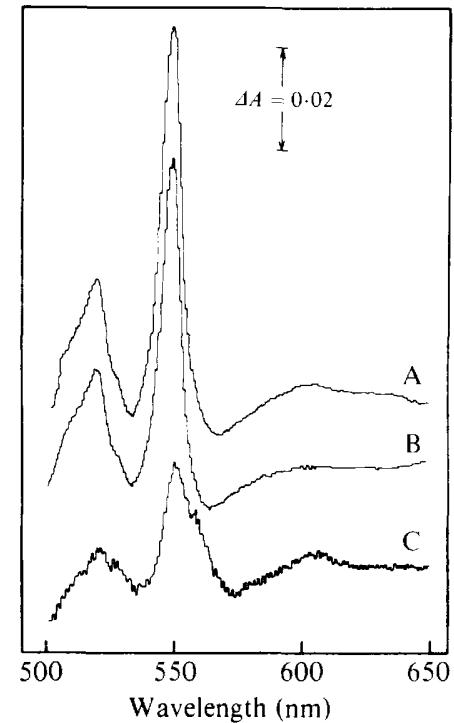

Fig. 1

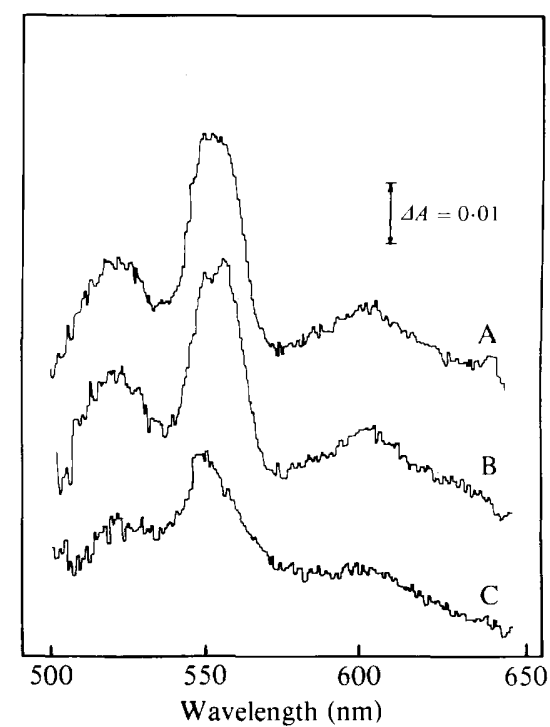

Fig. 2

Fig. 1. Dithionite-reduced minus oxidized difference spectra of extracts from lithotrophic cells. Washed cells from 61 exponential culture in $5 \mathrm{ml}$ phosphate buffer $(100 \mathrm{mM}, \mathrm{pH} \mathrm{7.0})$ were disrupted by sonication and fractionated as described in Methods. The amounts of protein used were $5.6 \mathrm{mg}, 4.2 \mathrm{mg}$ and $1.3 \mathrm{mg}$, respectively, from crude (A), soluble (B) and membrane (C) extracts.

Fig. 2. Dithionite-reduced minus oxidized difference spectra of extracts from organotrophic cells. Washed cells from 11 exponential culture in $4.5 \mathrm{ml}$ phosphate buffer $(100 \mathrm{mM}, \mathrm{pH} \mathrm{7.0})$ were processed as described in Methods. The amounts of protein used were $3.3 \mathrm{mg}, 1.6 \mathrm{mg}$ and $1.7 \mathrm{mg}$, respectively, from crude (A), membrane (B) and soluble (C) extracts.

Table 1. Distribution of cytochrome $c$ in extracts prepared from lithotrophic and organotrophic cells

The specific absorbance values tested refer to absorbance divided by the appropriate quantities of crude-extract protein in each case. Absorbance values were obtained from the dithionite-reduced minus oxidized difference spectra in Figs 1 and 2. Crude lithotrophic and organotrophic protein values also derive from Figs 1 and 2 respectively.

\begin{tabular}{|c|c|c|c|}
\hline \multirow[b]{2}{*}{ Cell state } & \multirow[b]{2}{*}{ Fraction } & \multicolumn{2}{|c|}{ Absorbance of cytochrome $c$} \\
\hline & & $\begin{array}{c}10^{3} \times \text { Specific absorbance } \\
\left(A \text { units } \mathrm{mg}^{-1}\right)\end{array}$ & Relative absorbance \\
\hline Lithotrophic & $\begin{array}{l}\text { Crude extract } \\
\text { Membrane } \\
\text { Soluble }\end{array}$ & $\begin{array}{r}17 \cdot 3 \\
2 \cdot 8 \\
14 \cdot 4\end{array}$ & $\begin{array}{l}1 \cdot 00 \\
0 \cdot 16 \\
0 \cdot 83\end{array}$ \\
\hline Organotrophic & $\begin{array}{l}\text { Crude extract } \\
\text { Membrane } \\
\text { Soluble }\end{array}$ & $\begin{array}{l}1 \cdot 4 \\
1 \cdot 3 \\
0 \cdot 2\end{array}$ & $\begin{array}{l}1 \cdot 00 \\
0 \cdot 93 \\
0 \cdot 14\end{array}$ \\
\hline
\end{tabular}

The addition of thiosulphate to a crude lithotrophic extract resulted in reduction of both cytochrome $c_{548}$ and cytochrome $a_{603}$ (Fig. $3 a$ ). Observed maximal reduction levels in each case (after $30-40 \mathrm{~min}$ ) were at least $60 \%$ of corresponding dithionite-reducible levels. Thiosulphate did not serve as a reductant of cytochromes associated with lithotrophic membranes in the absence of cytochrome $c_{548}$ and/or other soluble components of thiosulphate-grown cells (Fig. $3 b$ ). Extensive reduction of cytochrome $c_{548}$ by thiosulphate readily occurred in a preparation freed of membranes by high-speed centrifugation (Fig. $3 c$ ). Furthermore, electron flow from thiosulphate to cytochrome $a_{603}$ was observed after reconstitution of the soluble and membrane 


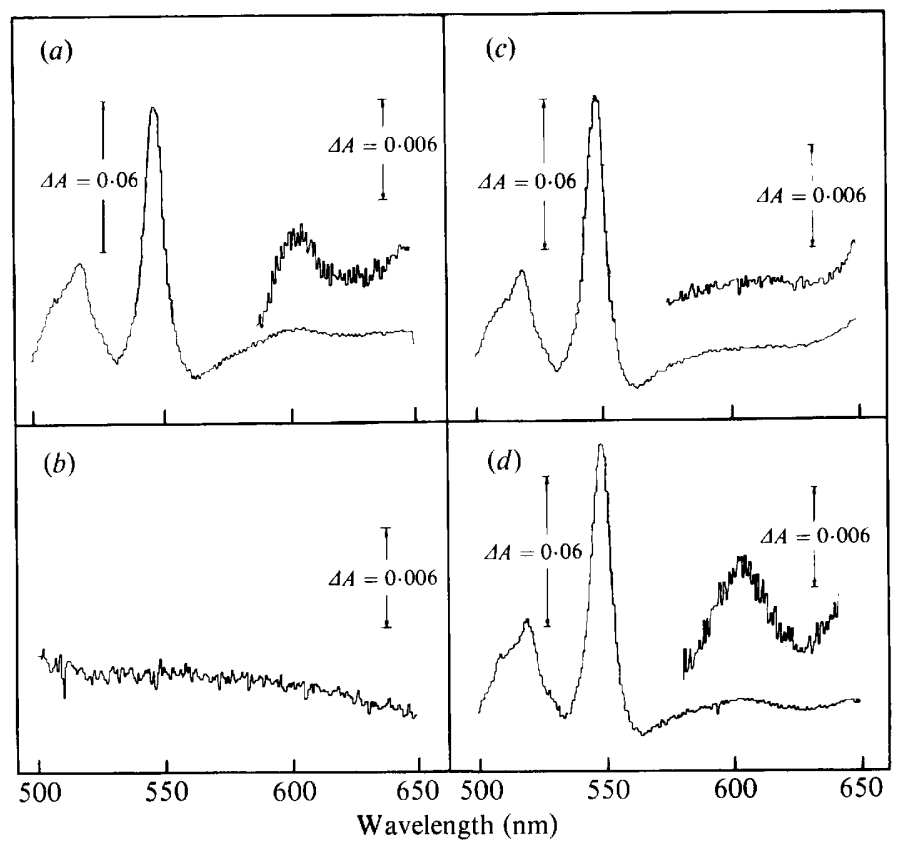

Fig. 3. Thiosulphate-reduced minus oxidized difference spectra of cytochromes in crude (a), membrane $(b)$, soluble $(c)$ and reconstituted membrane plus soluble $(d)$ fractions from lithotrophic cells. The total protein concentrations were $11.2 \mathrm{mg}, 2.6 \mathrm{mg}, 8.4 \mathrm{mg}$ and 2.6 plus $8.4 \mathrm{mg}$, respectively. Note the differences in computer attenuation of the data presented. Reduced spectra were recorded after establishment of anaerobiosis with reductant at $30 \mathrm{~min}$. Additional experimental details are given in Methods.

Table 2. Extent of cytochrome reduction by $20 \mathrm{mM}$-succinate in cell-free lithotrophic and organotrophic preparations

Data were derived from reduced minus oxidized spectra with dithionite or succinate as reductant. In the latter case, scans were repeated until peak absorbancies remained stable.

\section{Fraction tested}

Organotrophic membranes
Lithotrophic membranes
Lithotrophic soluble
Lithotrophic soluble +
organotrophic membranes
Lithotrophic soluble +
lithotrophic membranes

Succinate : dithionite reduction ratio

$\begin{array}{cccc}\text { Cyt } a_{603} & \text { Cyt } b_{560} & \text { Cyt } c_{550} & \text { Cyt } c_{548} \\ 0.92 & 0.44 & 0.73 & - \\ 0.88 & 0.38 & 0.76 & - \\ - & - & - & 0 \\ 0.94 & - & - & 0.91 \\ 0.93 & - & - & 0.86\end{array}$

fraction (Fig. $3 d$ ). Likewise, cytochrome $a_{603}$ associated with organotrophic membranes was reduced by thiosulphate in the presence of cytochrome $c_{548}$ and other soluble components of lithotrophic origin.

Succinate proved to be almost as efficient a reductant of cytochromes as dithionite in both lithotrophic and organotrophic membranes (Table 2). Extensive reduction of soluble cytochrome $c_{548}$ by succinate was also obtained, but only in the presence of membrane-associated intermediates (Table 2). The latter results confirm and extend earlier studies on succinate oxidation in cell-free extracts (Loya et al., 1982).

\section{Partial characterization of thiosulphate: cytochrome c oxidoreductase activity in membrane- depleted preparations from lithotrophic cells}

The reduction of soluble cytochrome $c_{548}$ by thiosulphate in a membrane-depleted preparation lacking detectable amounts of other cytochromes obeyed Michaelis-Menten kinetics, and 


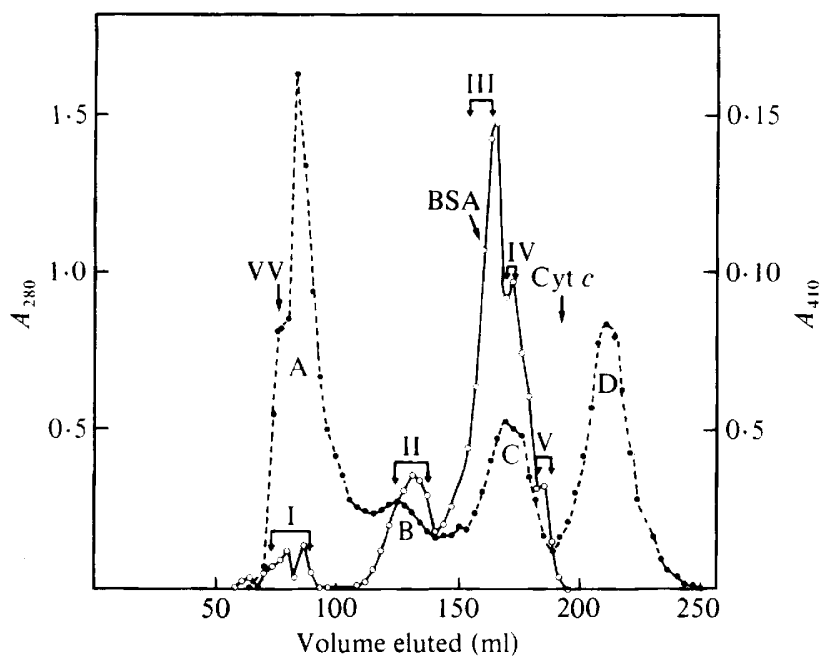

Fig. 4. Sepharose 6B gel chromatography of soluble components from lithotrophic cells. A 2 ml sample of soluble fraction containing $25.9 \mathrm{mg}$ protein was loaded on a $1.8 \times 95 \mathrm{~cm}$ column of Sepharose $6 \mathrm{~B}$ equilibrated at $4{ }^{\circ} \mathrm{C}$ with potassium phosphate buffer $(100 \mathrm{mM}, \mathrm{pH} 7.0)$ and eluted with the same buffer. Fractions $(3.2 \mathrm{ml})$ were collected at a flow rate of $15 \mathrm{ml} \mathrm{h}^{-1}$ and then analysed for protein $\left(A_{280},---\right)$ and cytochrome $\left(A_{410},-\right)$. The column was calibrated with Blue Dextran and standard proteins as described in Methods: VV, void volume.

was subject to inhibition by even modest concentrations of atabrine $\left(3 \times 10^{-4} \mathrm{M}\right)$. Apparent $K_{\mathrm{m}}$ and $V_{\max }$ values calculated from initial $(5 \mathrm{~min}$ ) rates of reduction in the presence of various thiosulphate concentrations in oxygenated medium were essentially the same [about $20 \mathrm{~mm}$ and 1-3 $\mathrm{nmol} \mathrm{min} \mathrm{m}^{-1}$ (mg protein $)^{-1}$ respectively] as values derived under strictly anaerobic conditions (i.e. air evacuated and replaced by pure argon). Dialysis of the soluble fraction against $100 \mathrm{~mm}$-phosphate buffer at $\mathrm{pH} 7 \cdot 0,4^{\circ} \mathrm{C}$, for $6 \mathrm{~h}$ neither enhanced nor inhibited the rate of $c_{548}$ reduction. Addition of various electron carriers, including NAD and crystalline cytochrome $c$, or electron donors such as reduced glutathione and reduced pyridine nucleotides did not affect reaction rates under either aerobic or anaerobic conditions.

\section{Size resolution of soluble cytochromes by gel filtration}

Passage of the soluble fraction from lithotrophic cells through a column of Sepharose 6B yielded four distinct peaks of material with absorbance at $280 \mathrm{~nm}$ (Fig. $4, A_{280}$ ). In and just behind the void volume was material exceeding $1000 \mathrm{kDal}$ in size (peak A). A second group of particles (peak B) eluted in the region where ribulose-1,5-biphosphate carboxylase and other large protein molecules were expected to emerge (Charles \& White, 1976). A third $A_{280}$ band was detected in the 15-80 kDal region (peak $\mathrm{C}$ ), whereas the fourth (and last) band to emerge (peak D) consisted of molecules of less than $15 \mathrm{kDal}$. Based on the $A_{410}$, cytochromes were associated with all but the smallest particles (i.e. peak D) recovered from the column (Fig. 4). The dithionite-reduced minus oxidized difference spectrum of pooled fractions from size region A (pool I) showed $\alpha$-absorption maxima at $603 \mathrm{~nm}, 560 \mathrm{~nm}$, and $550 \mathrm{~nm}$; these fractions failed to accept thiosulphate electrons. These latter cytochromes are of little interest since they appear to be intimately associated with fragments of cell membranes which were not removed during preliminary high-speed centrifugation of the large-scale preparation. By contrast, pools of fraction containing $A_{410}$ material from size regions B (pool II) and C (pools III, IV, V) were uniquely of the $c$-type of cytochrome and capable of undergoing reduction by thiosulphate to varying extents (Table 3). The percentage of thiosulphate-reducible soluble cytochromes appeared to increase with decreasing particle size and only particles less than about $50 \mathrm{kDal}$ exhibited $\alpha$-maxima at $548 \mathrm{~nm}$ (Fig. 4, Table 3). It should be stressed that none of the soluble $c$ type cytochromes in lithotrophic extracts of Thiobacillus A2N eluted with or behind soluble cytochrome $c$ of mammalian origin. Moreover, purified complexes containing $c$-type carriers exhibited the same thiosulphate : cytochrome $c$ oxidoreductase activity under anaerobic and 
Table 3. Characterization of soluble c-type cytochrome after size resolution of lithotrophic soluble fraction on Sepharose $6 B$

$\begin{array}{cccc}\begin{array}{c}\text { Fraction } \\ \text { pool tested }\end{array} & \begin{array}{c}\text { Size } \\ \text { region* }\end{array} & \begin{array}{c}\alpha \text {-Absorption } \\ \text { maximum }(\mathrm{nm})\end{array} & \begin{array}{c}\text { Extent of reduction } \\ \text { by thiosulphate }(\%) \dagger\end{array} \\ \text { II } & \text { B } & 549 & 8 \\ \text { III } & \text { C } & 550 & 47 \\ \text { IV } & \text { C } & 548 & 67 \\ \text { V } & \text { C } & 548 & 77\end{array}$

* See Fig. 4.

$\dagger$ Percentage of dithionite-reducible cytochrome reduced after prolonged exposure to 20 mM-thiosulphate.

aerobic conditions in the total absence of additional reductants. Considerable efforts were made to dissociate soluble lithotrophic complexes containing $c$-type cytochromes into subunits of smaller size by treatment with various detergents. None of these efforts were successful. For example, chromatography of lithotrophic soluble material on Sepharose 6B in the presence of the non-ionic detergent Brij $30(0 \cdot 1 \% \mathrm{v} / \mathrm{v}$ in $0 \cdot 1 \mathrm{M}-\mathrm{KCl})$ had no significant effect on the elution profile of cytochromes in the B and C size regions (see Fig. 4), but did effect drastic changes in the elution of bulk $A_{280}$ material. Similar results were obtained with anionic, cationic and other non-ionic detergents.

Due to the relatively low concentrations of $c$-type cytochromes in the soluble fraction of organotrophically cultured cells, it was necessary to work with much higher inputs $(196 \mathrm{mg}$ extract protein) and a larger $(3.5 \times 95 \mathrm{~cm})$ column in order to obtain a comparable sizeresolution profile. As before (Fig. 4), cytochrome-containing membrane fragments eluted with and immediately behind the void volume. However, in contrast to the result obtained with the high-speed soluble fraction from lithotrophically grown cells, region B proteins did not constitute a distinct peak. Nor, based on the $A_{410}$, were cytochrome-containing particles detectable in this region of the chromatogram. In fact, all of the soluble cytochromes present in high-speed supernatants of organotrophic origin emerged in the C region (i.e. 15-80 kDal). Moreover, the $\alpha$ absorption maximum of the proximal (i.e. largest) cytochrome-containing particles to elute in region $\mathrm{C}$ was at $556 \mathrm{~nm}$, suggesting the possible presence of a soluble $b$-type cytochrome (Poole $\&$ Haddock, 1975). Nevertheless, here too, the smallest cytochromes detected in the 40-15 kDal sub-region absorbed maximally at $548 \mathrm{~nm}$ and underwent extensive reduction by thiosulphate.

\section{DISCUSSION}

The present studies confirm previous conclusions reached on the basis of studies with intact cells (Loya et al., 1982), namely that cytochromes of lithotrophically and organotrophically cultured Thiobacillus A2 differ mainly in that the former contain much larger amounts of soluble cytochrome $c_{548}$. Furthermore, our data suggest that the cytochrome $c_{548}$ carrier is not an integral protein of the membrane ' $a b c$ ' system, but is part of either an independent complex (or complexes) not bound to membranes, or a peripheral complex weakly associated with the membrane system. In any case, reconstitution experiments indicated that membrane-bound cytochromes could be reduced by the $c_{548}$ component and vice versa. Accordingly, electrons derived from thiosulphate must flow through cytochrome $c_{548}$ in order to reduce the membrane ' $a b c$ ' system. However, the growth history of the cells from which the membrane fraction was derived did not matter. Similarly, succinate-derived electrons were able to reduce $c_{548}$ only in the presence of the membrane fraction. The implication for similar in vivo processes is obvious. Given that the redox potentials of the pertinent haem carriers have not yet been measured, it is difficult to sequence them. Nevertheless, it seems reasonable to conclude that cytochrome $c_{548}$ mediates the electron flow from thiosulphate to oxygen for the purpose of energy generation, and is also a constituent of the system involved in reverse electron flow to NAD. Schemes basically similar to the one cited above have already been proposed in Thiobacillus neapolitanus (Saxena \& Aleem, 1972) and T. novellus (Aleem, 1966).

It was shown previously that lithotrophic cells of Thiobacillus A2N in the process of adapta- 
tion to growth on succinate fail to synthesize cytochrome $c_{548}$ at a detectable level. However, in contrast to other constituents of the thiosulphate oxidation system, programmed destruction of cytochrome $c_{548}$ does not occur during this process (Loya et al., 1982). Taken together with our present demonstration of significant (albeit low) amounts of cytochrome $c_{548}$ in cells cultured on succinate for many generations, the above findings suggest a possible role for this particular component in organotrophic metabolism in Thiobacillus A2. In this regard it may be significant to note that Silver \& Kelly (1976) have reported the presence of sulphite :cytochrome $c$ oxidoreductase activity in extracts of the same bacterium after pre-growth on an organic substrate (i.e. formate).

The $\dot{c}_{548}$ cytochrome is apparently part of a macromolecular complex containing thiosulphate-oxidizing activity. Similar findings were reported in $T$. novellus where the purified thiosulphate-oxidizing system was found to be associated with membrane vesicles (Aleem, 1965; Oh \& Suzuki, $1977 a, b$ ). In Thiobacillus A2, on the other hand, the particles containing $c$-type cytochrome appeared to be devoid of major lipid content since detergents normally expected to release proteins from lipoprotein complexes (Helenius \& Simons, 1975) and to disrupt proteinprotein interactions, failed to dissociate them into smaller subunits.

The partial inhibitory effect of atabrine on the thiosulphate oxidation process, together with apparent saturation kinetics of thiosulphate : cytochrome $c_{548}$ oxidoreductase activity, suggest that non-haem carriers are located in the thiosulphate respiratory chain prior to cytochrome $c_{548}$ and are part of the complex. Also of interest was the fact that purified particles were capable of lithotrophic oxidation under anaerobic as well as aerobic conditions in the absence of additional electron sources. Assuming that the in vitro particles studied here are valid models for the situation in vivo, these latter observations tend to rule out reductive cleavage (Peck, 1960; Peck \& Fisher, 1962) as the first step of thiosulphate dissimilation in Thiobacillus A2. Conclusive elucidation of the sulphur oxidation pathway in Thiobacillus A2 will have to await development of a cell-free system capable of a high rate of terminal oxidation of thiosulphate.

We wish to thank D. P. Kelly for his gift of Thiobacillus A2 and Ms Theresa Bertold for her technical assistance in these studies.

\section{REFERENCES}

ALEEM, M. I. H. (1965). Thiosulphate oxidation and electron transport in Thiobacillus novellus. Journal of Bacteriology 90, 95-101.

ALEEM, M. I. H. (1966). Generation of reducing power in chemosynthesis. III. Energy linked reduction of pyridine nucleotide in Thiobacillus novellus. Journal of Bacteriology 91, 729-736.

CHARLES, A. M. (1971). Effect of growth substrate on the enzymes of the citric and glyoxylic acid cycles in Thiobacillus novellus. Canadian Journal of Microbiology 17, 617-624.

Charles, A. M. \& White, B. (1976). Ribulose biphosphate carboxylase from Thiobacillus A2. Its purification and properties. Archives of Microbiology 108, 195-202.

Helenius, A. \& Simons, K. (1975). Solubilization of membranes by detergents. Biochimica et biophysica acta 415, 29-79.

Kula, T. J., Aleem, M. I. H. \& Wilson, D. F. (1975). Oxidation-reduction potentials of the cytochromes of Thiobacillus A2. Bacteriological Proceedings 75, 136.

Loya, S., YANKofsky, S. A. \& Epel, B. L. (1982). Lithotrophy to organotrophy conversion in Thiobacillus A2. Journal of General Microbiology 128, 865874.

OH, J. K. \& SUzUKI, I. (1977a). Isolation and charac- terization of a membrane-associated thiosulphateoxidizing system of Thiobacillus novellus. Journal of General Microbiology 99, 397-412.

OH, J. K. \& SUZUKI, I. (1977b). Resolution of a membrane-associated thiosulphate-oxidizing complex of Thiobacillus novellus. Journal of General Microbiology 99, 413-423.

PeCK, H. D., JR (1960). Adenosine 5'-phosphosulphate as an intermediate in the oxidation of thiosulphate by Thiobacillus thioparus. Proceedings of the National Academy of Sciences of the United States of America 46, 1053-1057.

PeCK, H. D., JR \& Fisher, E., JR (1962). The oxidation of thiosulphate and phosphorylation in extracts of Thiobacillus thioparus. Journal of Biological Chemistry 237, 190-197.

PoOle, R. K. \& HaDdock, B. A. (1975). Effects of sulphate-limited growth in continuous culture on the electron transport chain and energy conservation in Escherichia coli K12. Biochemical Journal 152, 537546.

SaXena, J. \& AleEm, M. I. H. (1972). Generation of reducing power in chemosynthesis. VII. Mechanism of pyridine nucleotide reduction by thiosulphate in the chemoautotroph Thiobacillus neapolitanus. Archives of Microbiology 84, 317-326.

Silver, M. \& Kelly, D. P. (1976). Rhodanese from 
Thiobacillus A2: catalysis of reactions of thiosulphate with dihydrolipoate and dihydrolipoamide. Journal of General Microbiology 97, 277-284.

SMITH, A. J. \& HoARE, D. S. (1977). Specialist phototrophs, lithotrophs and methylotrophs: a unity among a diversity of procaryotes? Bacteriological Reviews 41, 419-448.

TAYLOR, B. F. \& HOARE, D. S. (1969). A new facultative Thiobacillus and a re-evaluation of the heterotrophic potential of Thiobacillus novellus. Journal of Bacteriology 100, 487-497.
Tikhonova, G. V., Lisenkova, L. L., Doman, N. G. \& SkulacheV, V. P. (1967). Electron transport pathways in Thiobacillus ferrooxidans. Biochemistry (English translation of Biokhimiya) 32, 599-605.

Tonge, G., KNowles, C. J., Harrison, D. E. F. \& HigGins, I. J. (1974). Metabolism of one-carbon compounds: cytochromes of methane and methanol utilizing bacteria. FEBS Letters 44, 106-110.

Trudinger, P. A. (1961). Thiosulphate oxidation and cytochromes in Thiobacillus. Biochemical Journal 78, 673-680. 